\title{
Anatomical Evidence that the Superior Colliculus Controls Saccades through Central Mesencephalic Reticular Formation Gating of Omnipause Neuron Activity
}

\author{
Niping Wang, ${ }^{1,2}$ Eddie Perkins, ${ }^{1,3}$ Lan Zhou, ${ }^{4}$ Susan Warren, ${ }^{1}$ and Paul J. May ${ }^{1,5,6}$ \\ Departments of ${ }^{1}$ Neurobiology and Anatomical Sciences, ${ }^{2}$ Periodontics and Preventive Sciences, ${ }^{3}$ Neurosurgery, ${ }^{4}$ Medicine, ${ }^{5}$ Neurology, and \\ ${ }^{6}$ Ophthalmology, University of Mississippi Medical Center, Jackson, Mississippi 39216
}

\begin{abstract}
Omnipause neurons (OPNs) within the nucleus raphe interpositus (RIP) help gate the transition between fixation and saccadic eye movements by monosynaptically suppressing activity in premotor burst neurons during fixation, and releasing them during saccades. Premotor neuron activity is initiated by excitatory input from the superior colliculus (SC), but how the tectum's saccade-related activity turns off OPNs is not known. Since the central mesencephalic reticular formation (cMRF) is a major SC target, we explored whether this nucleus has the appropriate connections to support tectal gating of OPN activity. In dual-tracer experiments undertaken in macaque monkeys (Macaca fascicularis), cMRF neurons labeled retrogradely from injections into RIP had numerous anterogradely labeled terminals closely associated with them following SC injections. This suggested the presence of an SC-cMRF-RIP pathway. Furthermore, anterograde tracers injected into the cMRF of other macaques labeled axonal terminals in RIP, confirming this cMRF projection. To determine whether the CMRF projections gate OPN activity, postembedding electron microscopic immunochemistry was performed on anterogradely labeled CMRF terminals with antibody to GABA or glycine. Of the terminals analyzed, $51.4 \%$ were GABA positive, $35.5 \%$ were GABA negative, and most contacted glycinergic cells. In summary, a trans-cMRF pathway connecting the SC to the RIP is present. This pathway contains inhibitory elements that could help gate omnipause activity and allow other tectal drives to induce the bursts of firing in premotor neurons that are necessary for saccades. The non-GABAergic cMRF terminals may derive from fixation units in the cMRF.
\end{abstract}

\section{Introduction}

Investigations of the circuitry underlying saccades, the fast movements that redirect the fovea from fixation on one point of interest to the next, have been particularly fruitful, providing a system in which the connectivity and signals of each of the neural elements involved in this behavior is well understood. Specifically, excitatory burst neurons (EBNs) are premotor cells that initiate the saccade. These are driven by descending inputs from the superior colliculus (SC). The nucleus raphe interpositus (RIP) contains glycinergic omnipause neurons (OPNs) that fire tonically during fixation, but stop abruptly just before and during saccadic eye movements in all directions (Cohen and Henn, 1972; Luschei and Fuchs, 1972; Keller, 1974). These OPNs monosynaptically inhibit EBNs and inhibitory burst neurons (IBNs), and help to prevent the occurrence of unwanted saccades during fixation (Nakao et al., 1980; Evinger et al., 1982; Strassman et al., 1987;

\footnotetext{
Received May 24, 2011; revised July 16, 2013; accepted Aug. 29, 2013.

Author contributions: S.W. and P.J.M. designed research; N.W., E.P., L.Z., S.W., and P.J.M. performed research; N.W., E.P., L.Z., and P.J.M. analyzed data; N.W., S.W., and P.J.M. wrote the paper.

This work was supported by National Institutes of Health Grant EY014263. We thank Glen Hoskins, Dr. Olga Golanov, and Jinrong Wei for helping to make this study possible through their excellent technical support. The authors declare no competing financial interests.

Correspondence should be addressed to Dr. Paul J. May, Department of Neurobiology and Anatomical Sciences, University of Mississippi Medical Center, 2500 North State Street, Jackson, MS 39216. E-mail: pmay@umc.edu. DOI:10.1523/JNEUROSCI.2726-11.2013

Copyright $\odot 2013$ the authors $\quad 0270-6474 / 13 / 3316285-12 \$ 15.00 / 0$
}

Kaneko, 1996). At saccade initiation, this inhibition is released at the same time that excitatory saccade signals from the SC reach premotor burst neurons (Robinson, 1975). Anatomical studies suggest that OPNs receive afferents derived mainly from the SC, and the midbrain and pontomedullary reticular formation (cat: Ito et al., 1984; Langer and Kaneko, 1984; monkey: Langer and Kaneko, 1990). However, which site supplies the requisite inhibitory inputs to RIP that gate OPN activity in conjunction with excitatory saccade-related inputs to EBNs and IBNs is not clear. The predorsal bundle, which contains the SC efferent fibers targeting both OPNs and premotor neurons, is presumed to be excitatory (Vidal et al., 1988; Mooney et al., 1990; Horn et al., 1994), so the SC cannot directly gate RIP activity. Presumably, SC outputs gate OPN activity through intermediary inhibitory neurons (Hepp et al., 1989; Gandhi and Keller, 1999; Shinoda et al., 2008).

The central mesencephalic reticular formation (cMRF) is also part of the saccade circuitry (Cohen and Büttner-Ennever, 1984; Cohen et al., 1985). Retrograde tracer studies suggest the cMRF provides the RIP with input (Langer and Kaneko, 1984, 1990), its activity is dominated by its inputs from the SC (Moschovakis et al., 1988a,b; Chen and May, 2000; Waitzman et al., 2000a,b; Cromer and Waitzman, 2006), and it contains GABAergic neurons (Araki et al., 1984, Wang et al., 2010; Appell and Behan, 1990). Since OPNs receive numerous contacts from GABAergic efferents (Horn et al., 1994), we hypothesized that the cMRF may send 
GABAergic inputs to RIP to suppress OPNs. If these cMRF projections receive tectal input, then the cMRF could assist the SC by gating OPN activity for saccade generation.

As described previously in brief (Wang et al., 2009), we used dual-tracer and single-tracer experiments in Macaca fascicularis monkeys to test whether the tectoreticular projection contacts cMRF neurons that supply RIP and to confirm that the cMRF projection actually targets the RIP, respectively. To further investigate the nature of this projection, tracer-labeled terminals underwent electron microscopic (EM) examination, and GABA and glycine postembedding immunohistochemistry was used to characterize putative inhibitory presynaptic and postsynaptic elements in the RIP.

\section{Materials and Methods}

Surgery. All animal procedures were undertaken in accordance with the animal care and use guidelines of the NIH, including the Principles of Laboratory Care, and with the approval of the University of Mississippi Medical Center Institutional Animal Care and Use Committee. Ten $M$. fascicularis monkeys (8 male and 2 female) underwent surgeries performed with sterile technique under isoflurane anesthesia (1-3\%), supplemented with a preemptive analgesic (carprofen, $3.0 \mathrm{mg} / \mathrm{kg}$ ). Animals were initially sedated with ketamine $\mathrm{HCl}$ (10 mg/kg, i.m.). Atropine sulfate $(0.05 \mathrm{mg} / \mathrm{kg}$, i.m.) was administered to control secretions, and dexamethasone $(0.4 \mathrm{mg}$, i.v. $)$ was given to minimize cerebral edema. Core temperature, respiration, heart rate, and blood $\mathrm{O}_{2}$ saturation were monitored and maintained within physiological levels during the surgical procedures. After the incisions were closed, the wound edges were infused with Sensorcaine. Buprenex $(0.01 \mathrm{mg} / \mathrm{kg}$, i.m. ) was administered as a postsurgical analgesic.

In the dual-tracer cases $(n=3)$, we injected biotinylated dextran amine (BDA; 10,000 molecular weight; Invitrogen) into the SC on the left side and wheatgerm agglutinin (WGA)-conjugated horseradish peroxidase (HRP; Vector Laboratories) into the midline nucleus RIP. Animals were placed in a stereotaxic head frame, and cortex overlying the midbrain and anterior cerebellar vermis was aspirated to allow direct visualization of the surface of the SC and the medial tentorium. The tip of a 1.0 $\mu l$ Hamilton microsyringe attached to a micromanipulator was centered in the intermediate layer of the SC, $1.0-1.5 \mathrm{~mm}$ below the surface, and was used to inject $0.1-0.2 \mu \mathrm{l}$ of a $10.0 \%$ solution of BDA at two to three different sites. Upon completion of the injection, the aspirated cortical cavity was filled with hydrated gelfoam. The overlying muscles and skin were reapproximated and stabilized with Vicryl suture. A second surgery targeted the RIP 14-20 d later. The scalp was reopened, and the gelfoam was removed. The tentorium was visualized, cut, and retracted. A stereotaxically placed $1.0 \mu \mathrm{l}$ Hamilton microsyringe was used to make the injection ( $0.02 \mu \mathrm{l}$ of a solution containing $2.0 \%$ WGA-HRP) by use of a transcerebellar approach. The postsurgical procedure was the same as for the first surgery.

In the single-tracer cases, we injected BDA $(n=4)$ or Phaseolus vulgaris leucoagglutinin (PhaL; $n=2$; Vector Laboratories) into the cMRF. The same presurgical, surgical, and anesthetic procedures were used as described above. Pressure injections of BDA were made with a $1.0 \mu \mathrm{l}$ Hamilton microsyringe attached to a micromanipulator that was driven through the pulvinar, as previously described (Wang et al., 2010). The coordinates used were based on previous descriptions (Cohen et al., 1985; Chen and May, 2000; Paxinos et al., 2000). For these BDA injections, $0.1-0.2 \mu \mathrm{l}$ of a $10.0 \%$ solution of BDA (Invitrogen) was delivered into the left cMRF along each of one or two penetrations. For the injection of PhaL, a $2.0 \%$ solution in $0.01 \mathrm{M}, \mathrm{pH} 8.0, \mathrm{PBS}$ solution was injected by means of iontophoresis. The PhaL solution was held in a glass micropipette with a tip diameter of $20 \mu \mathrm{m}$. A positive current of $7 \mathrm{~mA}$ was passed through the PhaL solution for $10 \mathrm{~min}$ per injection site (50\% duty cycle, $7 \mathrm{~s} /$ pulse). Two sites were injected. A negative continuous backing current was applied during the time when the micropipette was being advanced into or removed from the brain. The same postinjection procedures as outlined above were followed. As a control for fiber of passage uptake, we also analyzed a case in which just the SC was injected with $\mathrm{BDA}$, following the procedure described above for dual-tracer first injections.

Perfusion, histochemistry and sampling. After a survival time of 2-3 weeks from the initial injection, the animals were sedated with ketamine $\mathrm{HCl}$ and deeply anesthetized with sodium pentobarbital $(50-70 \mathrm{mg} / \mathrm{kg}$, i.p.). They were then perfused transcardially with buffered saline, followed by fixative containing $1.0 \%$ paraformaldehyde and $1.5 \%$ glutaraldehyde in $0.1 \mathrm{M}, \mathrm{pH} 7.2$, phosphate buffer (PB). Each brain was blocked in the frontal plane, postfixed for a minimum of $1 \mathrm{~h}$, and stored in cold $\mathrm{PB}$.

Brainstem blocks from the dual-tracer cases were cut in the frontal plane on a vibratome (Leica) and retained in serial order. The $100 \mu \mathrm{m}$ sections were reacted first with tetramethylbenzidine (Sigma) to reveal the location of WGA-HRP-labeled cells. This reaction product was stabilized with diaminobenzidine (DAB; Sigma) to produce a brown reac- 
tion product. Next, the sections were incubated in avidin-HRP (Vector Laboratories) to reveal the BDA-labeled axons. This was visualized using the chromagen DAB intensified with cobalt chloride and/or nickel ammonium sulfate (Fisher Scientific) to create a black reaction product. Details of these procedures can be found in Perkins et al. (2009). Sections were counterstained with cresyl violet or cytochrome oxidase (WongRiley, 1979), dehydrated, and coverslipped for light microscopic (LM) inspection.

To demonstrate the BDA labeling following single injections in the cMRF or SC, the procedure described in Wang et al. (2010) was followed. Brain blocks were cut on a vibratome. The sections were arranged into three ordered series of 100- $\mu$ m-thick frontal sections. Two series of sections were reacted using avidin-HRP to locate the BDA, and then nickel/ cobalt-intensified DAB was used as the chromagen. One of these series was mounted, counterstained with cresyl violet, dehydrated, and coverslipped. It was used to guide the selection of EM samples in the second series. Under a stereomicroscope (Wild M8, Leica), small tissue blocks containing RIP were cut out of free-floating sections from the second series of sections and collected for EM analysis. A variation on the method described in Gerfen and Sawchenko (1984) was followed to demonstrate the PhaL labeling (for details, see Zhou et al., 2008). Sections were cut on a vibratome at $50 \mu \mathrm{m}$. Briefly, the PhaL was localized with biotinylated antibody. This complex was then visualized using an $\mathrm{ABC}$ kit (Vector Laboratories), followed by the nickel/cobalt DAB intensification procedure. Then sections were mounted, counterstained, and prepared for light microscopy in the same manner as the BDA-labeled sections. Samples with PhaL-labeled terminals were taken for EM analysis as described above.

Tissue processing for electron microscopic analysis. The tissue samples for EM were postfixed with $1.0 \%$ osmium tetroxide in $0.1 \mathrm{M}, \mathrm{pH} 7.0, \mathrm{~PB}$, stained en bloc with $2.0 \%$ uranyl acetate, then dehydrated and embedded in Durcupan using conventional techniques (Wang et al., 2010). After embedding, $1-\mu \mathrm{m}$-thick semithin sections were cut with glass knives on an ultramicrotome (Ultracut E, Reichert), counterstained with toluidine blue, and coverslipped for inspection. The blocks were then retrimmed and ultrathin silver/gold sections were cut with a diamond knife on an ultramicrotome (Ultracut UCT, Leica). For normal EM procedures on single (BDA or PhaL)-label material, sections were placed on copper mesh grids. The copper grids were stained with lead citrate for $30 \mathrm{~s}$. For double-label material, GABA or glycine postembedding immunohistochemical staining was performed on sections collected onto formvarcoated nickel $1 \times 2 \mathrm{~mm}$ slot grids. The grids were processed using first rabbit anti-GABA (1:250; Sigma) or rabbit anti-glycine (1:50; Millipore) and then anti-rabbit IgG (GE Healthcare) conjugated to $15 \mathrm{~nm}$ gold particles (Wang et al., 2010). The anti-glycine procedure tagged far fewer immunoreactive sites, even with increased concentration of antibody, perhaps because this smaller molecule is more difficult to cross-link through fixation.

Data analysis. Sections were drawn using a drawing tube mounted on an Olympus $\mathrm{BH} 2$ microscope. Areas of interest were digitally photographed with a Nikon DXM 1200F Digital Camera mounted on a Nikon Eclipse E600 microscope. Images were acquired using MetaMorph software (Universal Imaging) and adjusted to match those visualized through the microscope by means of Photoshop (Adobe). Ultrathin sections were examined, and labeled profiles were photographed with a transmission electron microscope (model 906, Zeiss). EM photographs of terminals were generally taken at magnifications of $21,560 \times$ (GABA) or $10,000 \times$ (glycine). For quantification of sections stained for GABA, the number of gold particles in $0.25 \mu \mathrm{m}^{2}$ samples taken from three or more regions over axon myelin sheaths, per grid, was counted to provide a background particle density for use as a baseline. We classified the terminals into GABA-positive $\left(\mathrm{GABA}^{+}\right.$; three or more times baseline), intermediate (more than baseline and less than three times baseline), and GABA-negative ( $\mathrm{GABA}^{-}$; less than or equal to baseline) categories. Somatic and dendritic profiles were classified into $\mathrm{GABA}^{+}$(two or more times baseline), intermediate ( $>$ baseline and less than two times baseline), and $\mathrm{GABA}^{-}$(less than or equal to baseline). For sections stained for glycine, the number of gold particles in $151.0 \mu \mathrm{m}^{2}$ sample regions that did not contain obvious labeled terminals was used to establish a
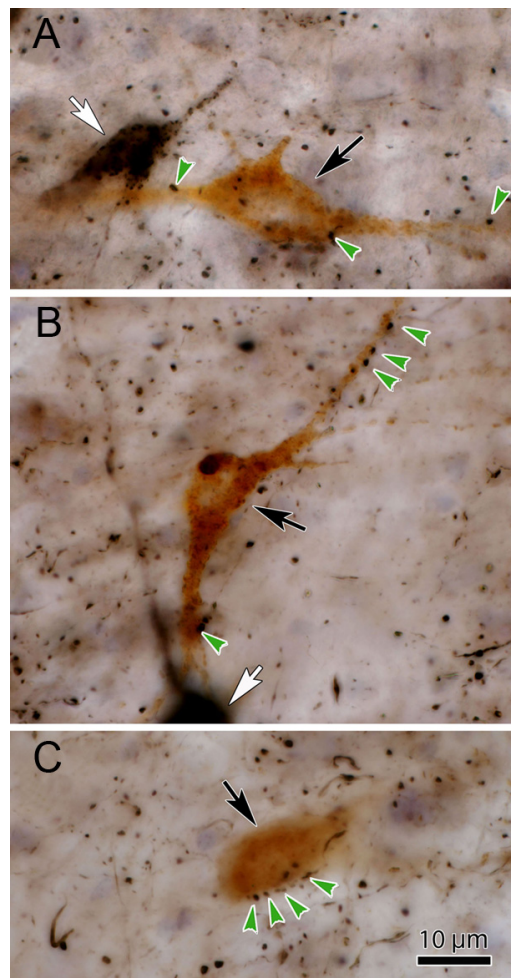

Figure 2. Photomicrographs of the WGA-HRP-labeled neurons show close associations with BDA-labeled terminals following dual-tracer injections. A-C, The light brown WGA-HRPlabeled reticuloraphe neurons (black arrows) are easily differentiated from the black BDAlabeled reticulotectal neurons ( $\boldsymbol{A}, \boldsymbol{B}$, white arrows). Close associations (green arrows) between these WGA-HRP-labeled reticuloraphe neurons and black, BDA-labeled tectoreticular boutons are common.

baseline. We classified terminals into glycine-positive (glycine ${ }^{+}$; three or more times baseline), intermediate (more than baseline and less than three times baseline), and glycine-negative (glycine ${ }^{-}$; less than or equal to baseline) categories. Somatic and dendritic profiles were classified into glycine $^{+}$(two or more times baseline), intermediate (more than baseline and less than two times baseline) and glycine ${ }^{-}$(less than or equal to baseline). The label for glycine was relatively low, resulting in a high percentage of postsynaptic profiles lying in the intermediate category. However, analysis of these profiles in semiserial sections revealed that they consistently displayed gold particles, indicating that they are indeed glycinergic.

\section{Results}

\section{Dual-tracer experiments}

Figure 1 shows a typical example from the dual-tracer cases. BDA was injected into the caudal part of left SC (Fig. 1d) to anterogradely label axon terminals, and WGA-HRP was injected into the nucleus RIP (Fig. $1 a-c$ ) to retrogradely label neurons. While the SC injection was confined within the target, and primarily involved the intermediate layers, spread from the RIP injection extended into the adjacent pontine reticular formation. Axon terminals that were anterogradely labeled with BDA (stipple) were revealed in the CMRF on both sides of the midbrain, but were much denser ipsilaterally than contralaterally (Fig. $1 A-C$ ). Other areas containing BDA-labeled terminals included the periaqueductal gray (PAG) and the contralateral SC. BDA can also transport retrogradely. Neurons that were retrogradely labeled with BDA (Fig. $1 A-C$, dots) were observed in the cMRF on both sides, with an ipsilateral predominance. Chen and May (2000) proposed that the region with dense overlap of anterograde and retrograde BDA labeling following SC in- 
jections represents the core of the cMRF. Neurons that had been retrogradely labeled from the WGA-HRP injection into the RIP (Fig. $1 A-C$, red diamonds) were also distributed on both sides of the cMRF. These reticuloraphe neurons fell within the tectoreticular terminal field. They had a much more widespread mediolateral distribution than the medially confined cMRF neurons projecting to the cervical spinal cord (Warren et al., 2008; Perkins et al., 2009). A small number of WGA-HRP-labeled neurons were also observed in the SC and PAG (Fig. $1 A-C$ ), as well as in the pontomedullary reticular formation (not illustrated).

The relationship between the anterogradely labeled tectal terminals and individual reticuloraphe neurons retrogradely labeled with WGA-HRP is shown in Figure 2. The light-brown WGA-HRPlabeled reticuloraphe cells (Fig. 2, black arrows) are easily differentiated from the black BDA-labeled reticulotectal neurons (Fig. 2, white arrows). Close associations (Fig. 2, arrowheads) between the boutons of black, BDA-labeled, tectoreticular axons and the brown WGAHRP-labeled reticuloraphe cells were frequently observed (Fig. 2A-C). In some cases, the tectoreticular terminals were lined up along neuronal somata (Fig. 2C) and dendrites (Fig. 2B). While EM confirmation of synaptic contact is needed, the manner in which the BDAlabeled boutons followed the contours of the dendrites and somata of the retrogradely labeled reticuloraphe neurons strongly supports the presence of synaptic interaction.

\section{cMRF injection-labeled terminals within RIP}

Due to the fact that the tracer in the RIP injections spread into the surrounding pontine reticular formation, the WGA-HRP might also have been picked up by axons terminating or passing adjacent to the nucleus. Consequently, we confirmed the presence of a cMRF-raphe projection by injecting anterograde tracers into the cMRF. After BDA injections into the cMRF, labeled axon terminals were observed in the expected brainstem regions, including the $\mathrm{SC}, \mathrm{PAG}$, and paramedian pontine reticular formation (PPRF; not illustrated), as well as in RIP. Figure 3 shows an example in which the BDA injection was centered in the cMRF (Fig. 3c). Labeled axons arborized densely within RIP (Fig. $3 b$ ). The terminal boutons of these axons showed numerous close associations (Fig. 3A-G, arrowheads) with the counterstained cells found within this nucleus, suggesting contact with somata and proximal dendrites. The appearance of these terminal arbors can also be appreciated in the photomicrographic evidence from material counterstained with cytochrome oxidase (Fig. $4 A, B$ ). The RIP lies on the midline, between the exiting abducens nerves (Fig. 4A). The cMRF axons arborized frequently among the RIP cells and displayed numerous en passant boutons (Fig. 4B). Nissl- stained RIP neurons, presumably omnipause neurons (Fig. $4 B$, arrows), were observed to be closely associated with BDAlabeled terminal boutons (Fig. 4C-E, arrowheads). These counterstained neurons are large (up to $30 \mu \mathrm{m}$ along their somatic long axis), contained round nuclei, and were generally multipolar. Closely associated terminals were often lined up along their somata (Fig. 4D) and proximal dendrites (Fig. 4C).

To exclude the possibility that the axon terminals observed following BDA injections in the cMRF were due to fiber-ofpassage or axon collateral uptake by predorsal bundle axons originating in the SC and terminating in RIP, PhaL injections were made in the cMRF of two additional cases. PhaL is a purely anterograde tracer, which is not generally taken up by fibers-of-passage. In this case, PhaL was injected into the center of cMRF (Fig. $5 c$ ). The number of PhaL-labeled terminals (stipple) observed in the RIP was somewhat smaller than with BDA injections, but they were still quite evident. PhaL-labeled terminals in close association with counterstained RIP neurons were once again commonly observed (Fig. 5A,C-E). Photographic evidence for these close associations can be found in Figure $4 F-H$ (arrowheads). As with the BDA-labeled boutons, PhaL-labeled terminals were found adjacent to both the dendrites (Fig. $4 G$ ) and somata (Fig. $4 F, H$ ) of cells in RIP. 


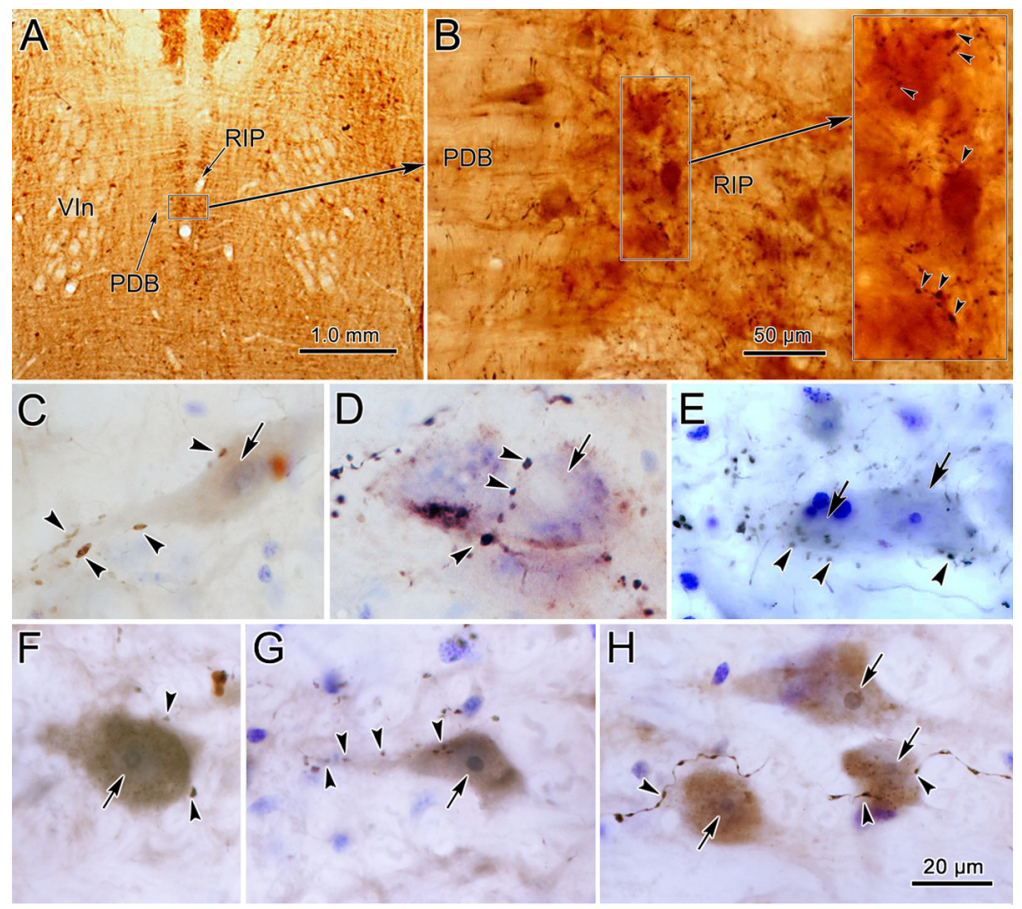

Figure 4. BDA-labeled and PhaL-labeled CMRF terminals within nucleus RIP. A, Location of RIP in a frontal section counterstained for cytochrome oxidase. Note its position between the exiting abducens nerves (VIn) and flanked by the predorsal bundle (PDB). B, At higher magnification, the arborization of BDA-labeled axons among the RIP cells is demonstrated (arrowheads in inset indicate boutons). $\mathbf{C}-\boldsymbol{E}$, BDA-labeled terminal boutons are closely associated (arrowheads) with Nissl-stained RIP neurons (arrows). $\boldsymbol{F}-\boldsymbol{H}$, PhaL-labeled cMRF terminal boutons are closely associated (arrowheads) with RIP neurons (arrows). The brown color of the cytoplasm of these cells is due to background staining. Scale bar: $\boldsymbol{H}$ (for $\boldsymbol{C}-\boldsymbol{H}$ ), $20 \mu \mathrm{m}$.

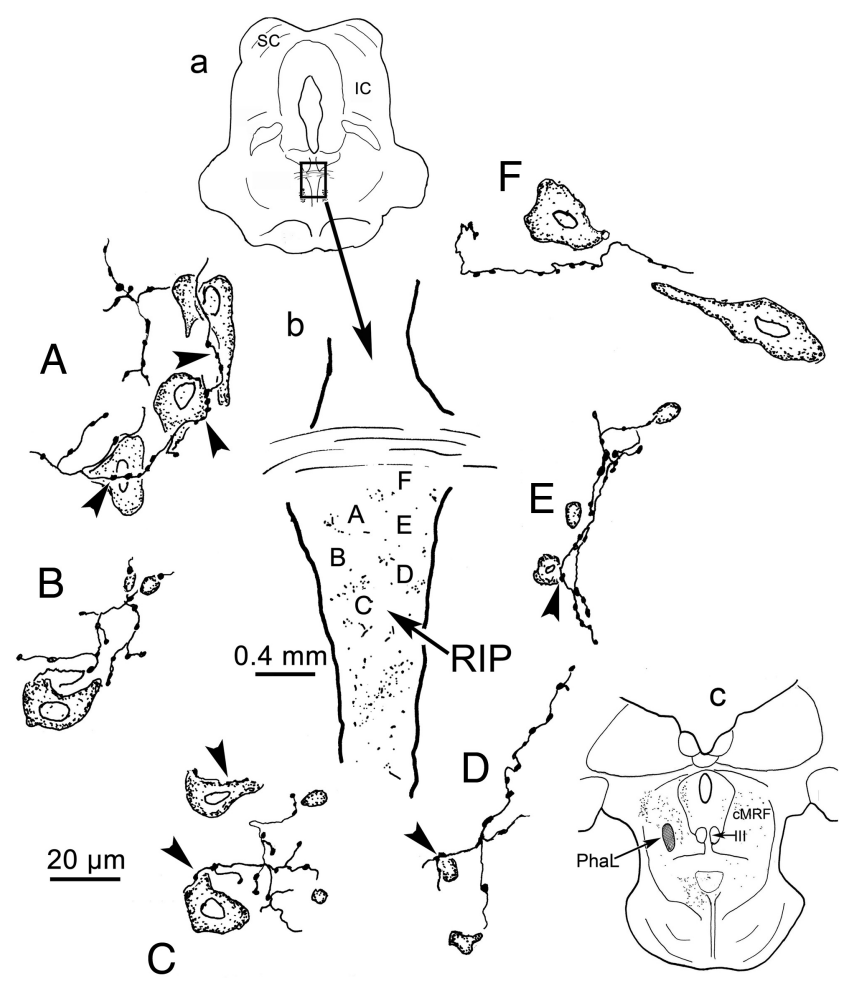

Figure 5. Drawings of PhaL-labeled CMRF reticuloraphe axon terminals and RIP neurons. The section illustrated is shown in $\boldsymbol{a}$. The outline of RIP is shown in $\boldsymbol{b}$. Labeled terminals (stipple), as well as the location of the illustrated examples, are indicated. The PhaL injection site is shown in c. Counterstained RIP neurons and their relationships with PhaL-labeled, reticuloraphe terminals are demonstrated in $\boldsymbol{A}-\boldsymbol{F}$. Close associations are indicated by arrowheads. IC, Inferior colliculus; III, oculomotor nucleus. Scale bar: $\boldsymbol{A}-\boldsymbol{F}, 20 \mu \mathrm{m}$.

\section{Ultrastructure and GABAergic nature of the reticuloraphe projection}

In the cases used for EM analysis, well confined BDA injection sites were located within the left cMRF (Fig. 6A,B). BDAlabeled axons and terminals (stipple) were found bilaterally in the pons (Fig. $6 \mathrm{C}-\mathrm{H}$ ). A portion of this label was distributed within the RIP, which lies on the midline between the rootlets of the exiting abducens nerve (Fig. 6C,E, $G$ ). Both anterogradely labeled terminals and retrogradely labeled neurons were revealed within the PPRF on both sides, with ipsilateral predominance. Samples were cut from RIP for EM analysis (Fig. $6 D, F, H$, small windows).

BDA-labeled reticuloraphe axon terminals $\left(\mathrm{At}^{*}\right)$ were identified under the EM by their greater electron density due to the reaction product in their cytoplasm, particularly in the vicinity of vesicular and other membranes (Fig. 7A,B). The terminal profiles varied from approximately round to oval in shape, and ranged in size between 0.6 and $2.3 \mu \mathrm{m}$ along their long axes. They were moderately to densely packed with small, clear vesicles. Both round and pleomorphic vesicles were observed in these terminals. Some profiles contained mainly round vesicles (Fig. 7A), while pleomorphic vesicles were more common in other profiles (Fig. 7B). Several (one to six) mitochondria were usually seen in these labeled terminals. Contacts between BDA-labeled terminals and their postsynaptic targets varied in appearance. Some showed symmetric contacts (Fig. $7 B$ ), while others were modestly asymmetric (Fig. $7 A$ ). Large and small dendrites, as well as somata, were observed among the profiles postsynaptic to BDA-labeled terminals. None of the BDAlabeled terminals were found to synapse on or be apposed to other BDA-labeled profiles.

Ultrathin sections from these tissue samples were processed by GABA-postembedding immunostaining to reveal GABAergic profiles. Due to their electron density, BDA-labeled terminals were still evident in this GABA-postembedding-immunostained tissue (Figs. $8,9,10$ ). Both GABA-positive terminals (Fig. 8A-C) and GABAnegative terminals (Fig. $8 D-F$ ) were observed among the BDAlabeled profiles in RIP. No obvious differences were seen between the profiles postsynaptic to the GABA-positive and GABAnegative terminals. In Figure $8 A-C$, GABA-positive, BDAlabeled terminals $\left(\mathrm{At}^{*}+\right)$ are overlain by numerous gold particles (Fig. $8 A-C$, black dots), produced by the postembedding procedure. Each apposes an adjacent dendritic profile, which was identified as GABA and BDA negative (Fig. 8, Den). Symmetric synapses (Fig. $8 A-C$, arrowheads) between these terminals and postsynaptic elements are evident. Samples of GABA-negative, BDA-labeled terminals are demonstrated in Figure $8 D-F\left(\mathrm{At}^{*}\right)$. Each of these terminals contacts a postsynaptic dendritic profile with a modestly asymmetric synapse (Fig. $8 D-F$, arrowhead), although the degree of asymmetry varies. The postsynaptic profiles were also identified as GABA negative (Fig. $8 D-F$, Den). In Figure $8 D$, a GABA-positive terminal (At+) and a GABApositive dendrite (Den + ) are indicated for comparison. Semise- 


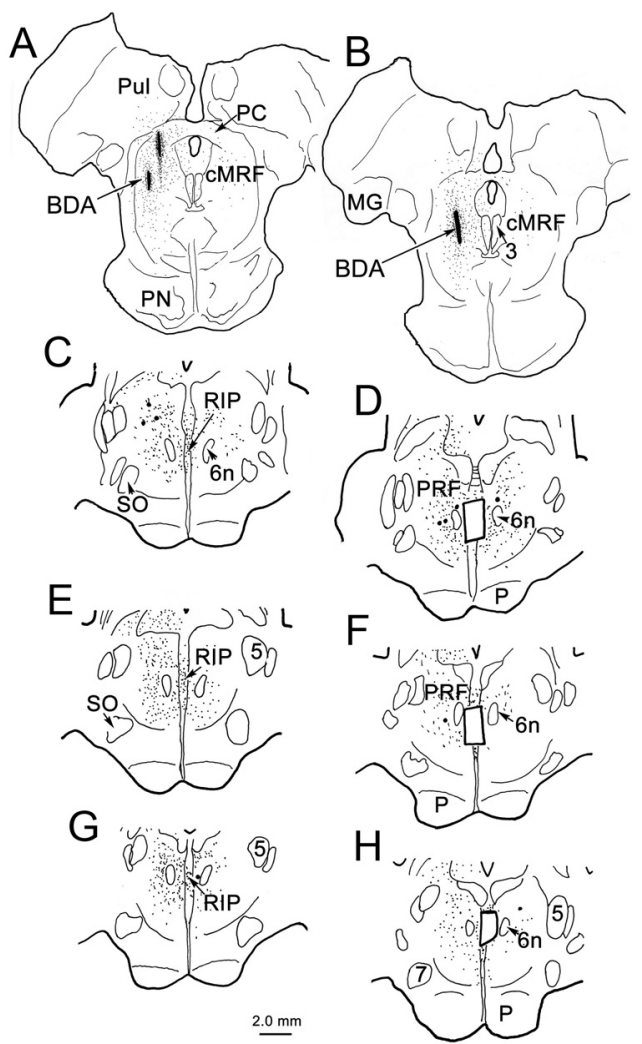

Figure 6. Distribution of anterogradely labeled axon terminals (stipple) and retrogradely labeled neurons (dots) following a BDA injection into monkey CMRF. A, B, Small BDA injection sites within CMRF. $\mathbf{C}-\boldsymbol{H}, \mathrm{BDA}$-labeled terminals were distributed in RIP, between the exiting sixth nerves (6n) and bilaterally in the PPRF, with a slight ipsilateral predominance. Small windows in $\boldsymbol{D}, \boldsymbol{F}$, and $\boldsymbol{H}$ demonstrate the areas where RIP samples were taken for EM analysis. $M G$, Medial geniculate; $P$, pyramid; $P C$, posterior commissure; $P N$, pontine nuclei; PRF, pontine reticular formation; Pul, pulvinar; $\mathrm{SO}$, superior olive; 3 , oculomotor nucleus; 5 , trigeminal nucleus; $6 n$; sixth nerve; 7 , facial nucleus.

rial sections were collected to confirm our quantitative categorization. Figure 9, $A$ and $B$, demonstrates two semiserial sections through a BDA-labeled, GABA-positive terminal $\left(A t^{*}+\right)$ that contacts a GABA-negative soma. The sections are separated by a $100 \mathrm{~nm}$ interval. The presence of GABA labeling in more than one section through the same profile indicates that our categorization of terminals was not unduly affected by variability in background staining. To control for the possibility that the GABA-negative terminals labeled following cMRF injection of BDA were due to the tracer being picked up by collicular axons passing through the injection site, we also analyzed tissue from a case in which PhaL was injected into the cMRF, since this tracer shows little fiber-of-passage uptake. The plates in Figure 9E-J, show that the same two terminal types were labeled. Anterogradely labeled terminals that were GABA positive (Fig. $9 E-G$, $A t^{*}+$ ), as well as GABA negative (Fig. $9 E-G, A t^{*}$ ), were present. The vesicles in the latter tended to be more uniformly spherical. Both types of terminals were associated with somata (Fig 9E, $J$ ) and with medium-sized (Fig. 9H) and small (Fig. 9F, G,I) dendrites.

We quantified our EM analysis of BDA-labeled terminals. A total of 120 BDA-labeled terminals were collected and photographed from both the single-labeled (BDA only) and doublelabeled (both BDA and GABA) material obtained from two cases. Sixty-three of these had evident synapses, of which $11.5 \%$ (7) contacted somata. The sizes (short axes) of the dendritic profiles
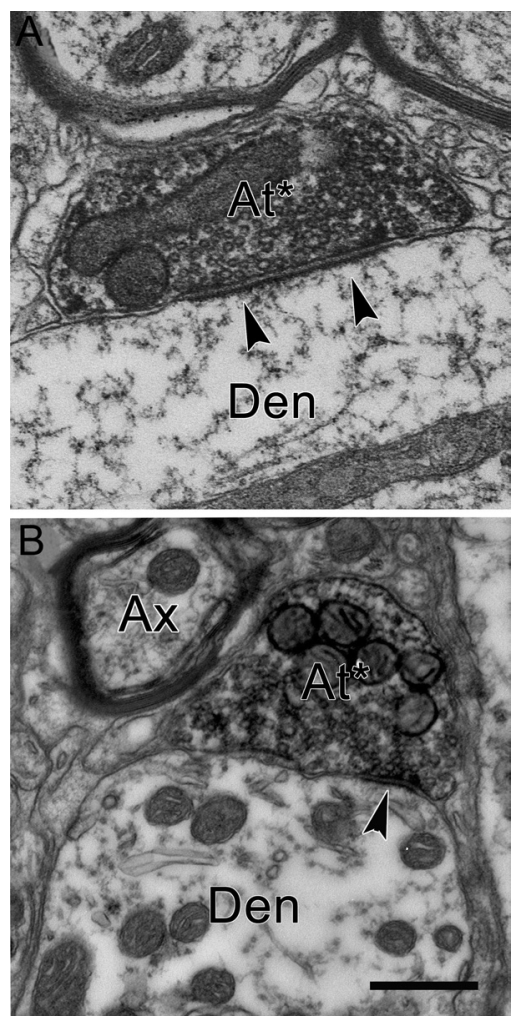

Figure 7. Electron micrographs of axon terminals in RIP labeled from a BDA injection of the CMRF. $\boldsymbol{A}$ and $\boldsymbol{B}$ are both from material processed for BDA only. BDA-labeled terminals ( $A t^{*}$ ) make asymmetric $(\boldsymbol{A})$ and symmetric $(\boldsymbol{B})$ synapses (arrowheads) with nonlabeled dendrites (Den). Round vesicles are more common in $\boldsymbol{A}$. Scale bar, $0.5 \mu \mathrm{m}$.

postsynaptic to these synaptic terminals varied between 0.5 and $4.0 \mu \mathrm{m}$. The dendrites were divided into two categories, more proximal dendritic profiles with short axes $\geq 3.0 \mu \mathrm{m}$, and more distal dendritic profiles with short axes $<3.0 \mu \mathrm{m}$. We found that $51.4 \%$ (33) of the BDA-labeled terminals contacted more proximal dendritic profiles, and $37.4 \%$ (23) contacted more distal dendritic profiles. Among 107 BDA-labeled terminals in the GABAstained material, $\sim 51.4 \%$ (55) of these labeled terminals could be categorized as GABA positive, and $35.5 \%$ (38) as GABA negative. The remaining $13.1 \%$ (14) fell into an intermediate category that we did not classify. Nearly all (98.4\%) of the profiles postsynaptic to the BDA-labeled terminals with an evident synaptic density were GABA negative.

In some cases, the EM samples were recut and processed to identify whether any of the BDA-labeled terminals were glycinergic. BDA-labeled reticuloraphe terminals were generally glycine negative (Fig. $10 A, D, \mathrm{At}^{*}$ ). This categorization was backed up by identifying the same terminal in serial sections (Fig. 10B,C,E,F). Quantitative analysis of 114 terminals indicated that $80 \%$ of the terminals displayed background levels of staining, and only $1 \%$ of the reticuloraphe terminals were clearly glycine positive, with three times the number of threshold particles present. The remaining 20\% had intermediate levels of GABA particle staining. As demonstrated in semiserial sections, these BDA-labeled profiles were sometimes overlain by gold particles in one section, but lacked them in the next, indicating they are glycine negative (Fig. 10 B, C,E, F). Only rarely were multiple particles seen over the same BDA-labeled glycine-positive terminal in adjacent sections (Fig. 10E,F, $\left.A t^{*}+\right)$. The profiles postsynaptic to the BDA-labeled terminals were often characterized as glycine positive, whether they were 


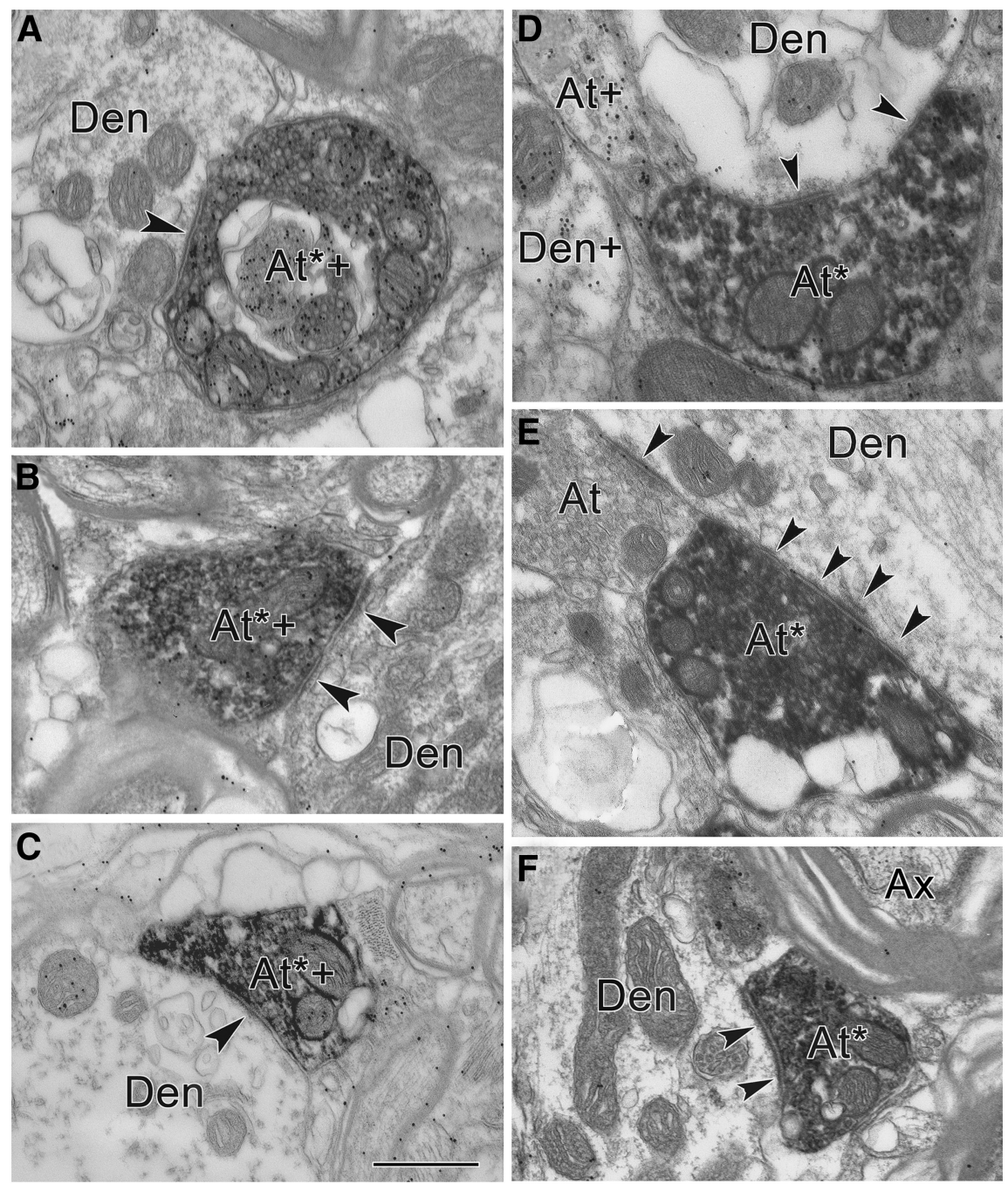

Figure 8. $\boldsymbol{A}-\boldsymbol{F}$, Electron micrographs of GABA-positive $(\boldsymbol{A}-\boldsymbol{C})$ and $\mathrm{GABA}$-negative $(\boldsymbol{D}-\boldsymbol{F})$ reticuloraphe axons. $\boldsymbol{A}-\boldsymbol{C}$, Postembedding GABA immunohistochemistry of BDA-labeled CMRF terminals in RIP. Most BDA-labeled axon terminals in RIP were GABA positive $\left(\mathrm{At}^{*}+\right.$ ). The BDA-labeled, GABA-positive terminals made symmetric contacts (arrowheads) with GABA-negative dendrites (Den). $\boldsymbol{D}-\boldsymbol{F}$, Other terminals labeled following CMRF injection were GABA negative (At*). These BDA-labeled profiles made asymmetric contacts (arrowheads) with GABA-negative profiles (Den). At, Unlabeled terminal; Ax, unlabeled axon. Scale bar, 0.5 $\mu \mathrm{m}$.

somata (Fig. 10E,F), larger dendrites (Fig. 10A,D), or smaller dendrites (Fig. $10 B, C$ ). Quantitative analysis indicated that of 37 postsynaptic profiles, $62 \%$ displayed levels of glycine particle staining above background levels, but only $14 \%$ reached the criterion of two times the threshold. Often, sections in which the number of glycine particles over a dendritic profile did not reach a criterion of two times the threshold proved to be glycinergic based on serial section analysis (Fig. 10B,C,E,F, At + ). These results are in agreement with the immunohistochemical characterization of RIP omnipause neurons by Horn et al. (1994), which demonstrated that they are glycinergic.

\section{Non-GABAergic nature of tectoraphe projection to RIP}

The SC is known to project to RIP (Büttner-Ennever et al., 1999). Since predorsal bundle axons on their way from the SC to the pons pass through and terminate in the $\mathrm{CMRF}$, it was possible that the labeling of terminals seen in RIP was due to fiber-of-passage or axon collateral uptake. To characterize the SC tectoraphe projection, we injected BDA into the SC (not illustrated) and compared the ultrastructure of the tectoraphe axon terminals in this case with those labeled in cMRF injections. The BDA injection into SC extended into its rostral end, and so would have included the proposed "fixation zone" (Munoz and Wurtz, 1993a,b). Anterogradely labeled axon terminals were distributed in all known tectal targets. BDA-labeled axons running in the predorsal bundle were found in the white matter along side of RIP, contralateral to the injection. A modest number of terminals were present in RIP, but terminals were relatively sparse in the reticular formation immediately adjacent to RIP. Twenty BDAlabeled terminals were collected from RIP blocks in this case. As shown in Figure 9, C and $D$, they contained somewhat larger, round vesicles. These terminals were often densely filled with vesicles, so that they presented as an array. Their contacts on postsynaptic profiles displayed distinctly asymmetric synaptic densities. GABA postembedding immunohistochemistry results showed these terminals to be exclusively GABA negative, although adjacent BDA-negative terminals were clearly GABA positive (Fig. 9C, At+). This agrees with the conventional expectation that predorsal bundle fibers are excitatory. The morphologies of labeled tectoraphe terminals and labeled cMRF reticuloraphe GABAnegative terminals were similar in that they both contained round vesicles and tended to make asymmetric contacts. However, tectoraphe terminals often displayed densely packed, ordered arrays of vesicles and made more distinctly asymmetric contacts (compare Figs. 8E,F, $9 C, D)$. These characteristics were occasionally present, but were much rarer in terminals labeled from cMRF injections. This suggests that some, but not all, of the GABA-negative terminals labeled following BDA injections of the cMRF may have been produced by fiber-of-passage labeling.

\section{Discussion}

The present study confirmed that the cMRF projects to RIP and revealed that the cMRF reticuloraphe axon terminals contain a large proportion of GABAergic elements, suggesting that the cMRF may directly suppress the activity of glycinergic OPNs in RIP (Fig. 10). The smaller, non-GABAergic contribution might be issued by another category of cMRF neuron, suggesting additional cMRF effects in RIP. Close associations between tectoreticular axon terminal boutons and reticuloraphe neurons found in cMRF suggest that in addition to directly triggering saccaderelated activity in the PPRF, the SC may indirectly disinhibit premotor burst neurons via a trans-cMRF parallel pathway in which the SC activates the cMRF inhibitory input to RIP.

\section{The cMRF sends inhibitory inputs to RIP}

As shown in Figure 11, the intermediate gray layer (SGI) of the SC contains cells with saccade-related activity that trigger eye move- 

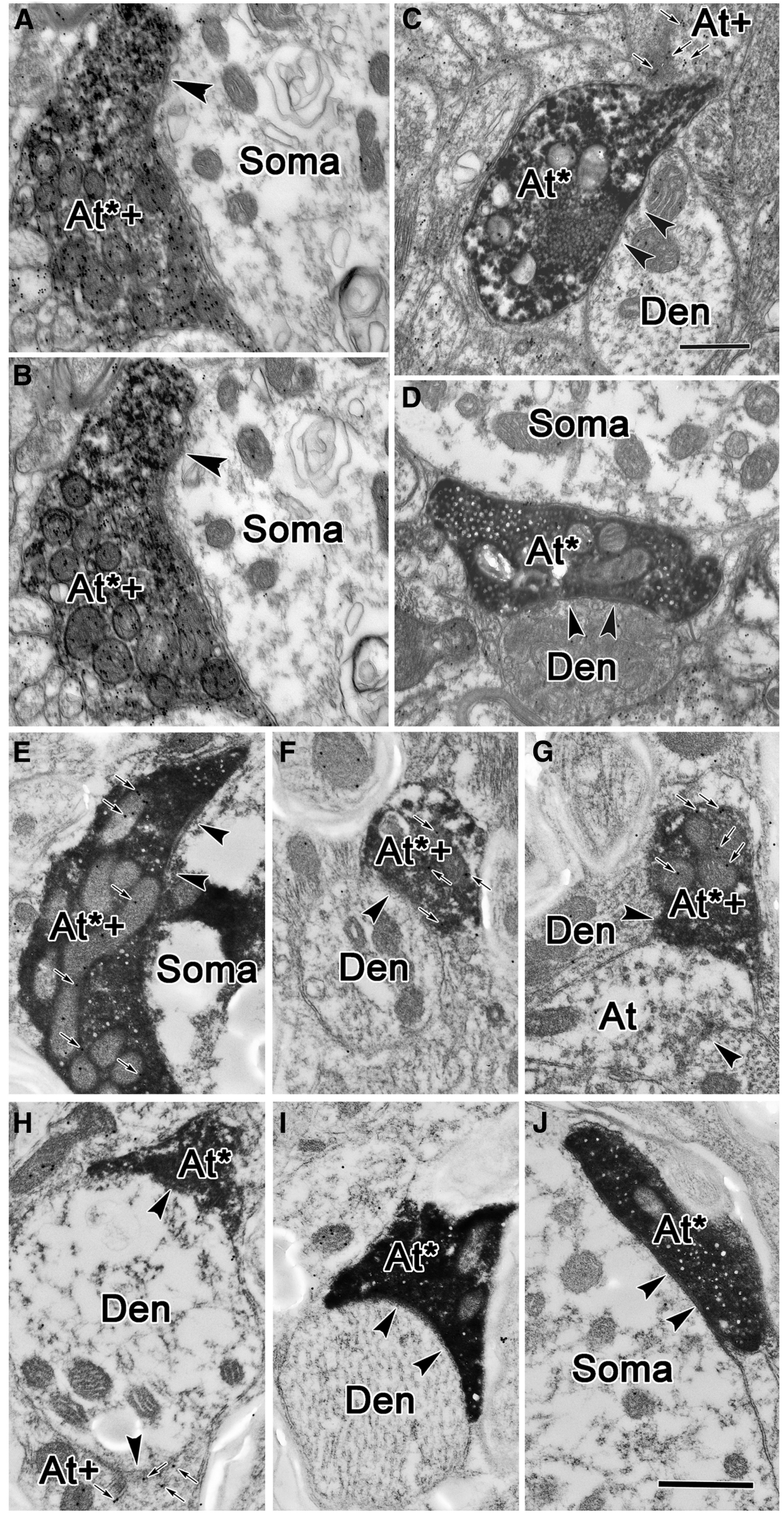

Figure 9. GABA staining of labeled terminals in the RIP. $\boldsymbol{A}, \boldsymbol{B}, \mathrm{A}$ double-labeled axonal terminal $\left(A t^{*}+\right)$, opposing an unlabeled somatic profile (Soma) was found in two semiserial sections. Interval between adjacent pictures is $\sim 100 \mathrm{~nm}$. C, D, Electron micrographs of anterogradely labeled, GABA-negative terminals in RIP following a BDA injection in the superior colliculus. ments via direct and/or indirect projections of predorsal bundle axons onto burst neurons (Wurtz and Goldberg, 1972; Raybourn and Keller, 1977; Sparks, 1978; Moschovakis et al., 1988a,b; Izawa et al., 1999; Keller et al., 2000; Sugiuchi et al., 2005). Excitatory input from the SC is paired with suppression of the tonic inhibitory signals that premotor burst neurons receive from OPNs, in order for an appropriate saccade-related burst to be manufactured in these neurons and their motoneuron targets. As the main outflow of the predorsal bundle is excitatory (Horn et al., 1994; Mooney et al., 1990; Vidal et al., 1988; present results), it is not likely that tectal efferents to RIP directly suppress OPN activity. However, saccade signals, like those carried by the predorsal bundle, must trigger mechanisms that turn off the discharge of OPNs. In fact, single-pulse electrical stimulation of SC produces hyperpolarization of OPNs at disynaptic latencies (Iwamoto et al., 1997; Yoshida et al., 2001). Furthermore, Chimoto et al. (1996) found that singlepulse electrical excitation of SGI is too weak to initiate monosynaptic latency saccades, unless combined with burst neuron disinhibition due to OPN suppression. Our dual-tracer experiment confirmed the presence of a trans-cMRF pathway from the SC to the RIP (Fig. 11) that is capable of OPN suppression.

Through the use of retrograde and anterograde tracers, our data confirm and extend the results of Langer and Kaneko (1990), showing a reticuloraphe projection by the cMRF. The cMRF's terminal field in RIP was the densest that we observed outside of the SC (Zhou et al., 2008; Wang et al., 2010). Moreover, reticuloraphe terminals were distributed more proximally on targeted dendrites than the cMRF reticulotectal terminals (Wang et al., 2010), suggesting an effective drive to OPNs. Approximately two-thirds of cMRF terminals in RIP labeled by BDA injections

\section{$\leftarrow$}

Synapses between BDA-positive, GABA-negative terminals (At*) and GABA-negative dendrites (Den) are indicated by arrowheads. In C, a GABA-positive, BDA-negative terminal $(A t+)$ is also shown. These profiles contain round, clear vesicles and make asymmetric contacts, although in $\boldsymbol{D}$ no synapse is apparent. Instead, a GABA-negative terminal lies adjacent to a GABA-negative somata (Soma). $\boldsymbol{E}$-J, PhaL-labeled CMRF terminals in the RIP can be both GABA positive $\left(\mathrm{At}^{*}+; \boldsymbol{E}-\boldsymbol{G}\right)$ or GABA negative $\left(A t^{*} ; \boldsymbol{H}-\boldsymbol{J}\right)$. GABA-positive terminals that were not labeled by the PhaL injection of the CMRF were also present $($ At $+; \boldsymbol{H})$. Small arrows indicate immunogold particles. Scale bars: $\boldsymbol{C}($ for $\boldsymbol{A}-\boldsymbol{D}), 0.5 \mu \mathrm{m}$; J (for $\boldsymbol{E}-\boldsymbol{J}), 0.5 \mu \mathrm{m}$. 

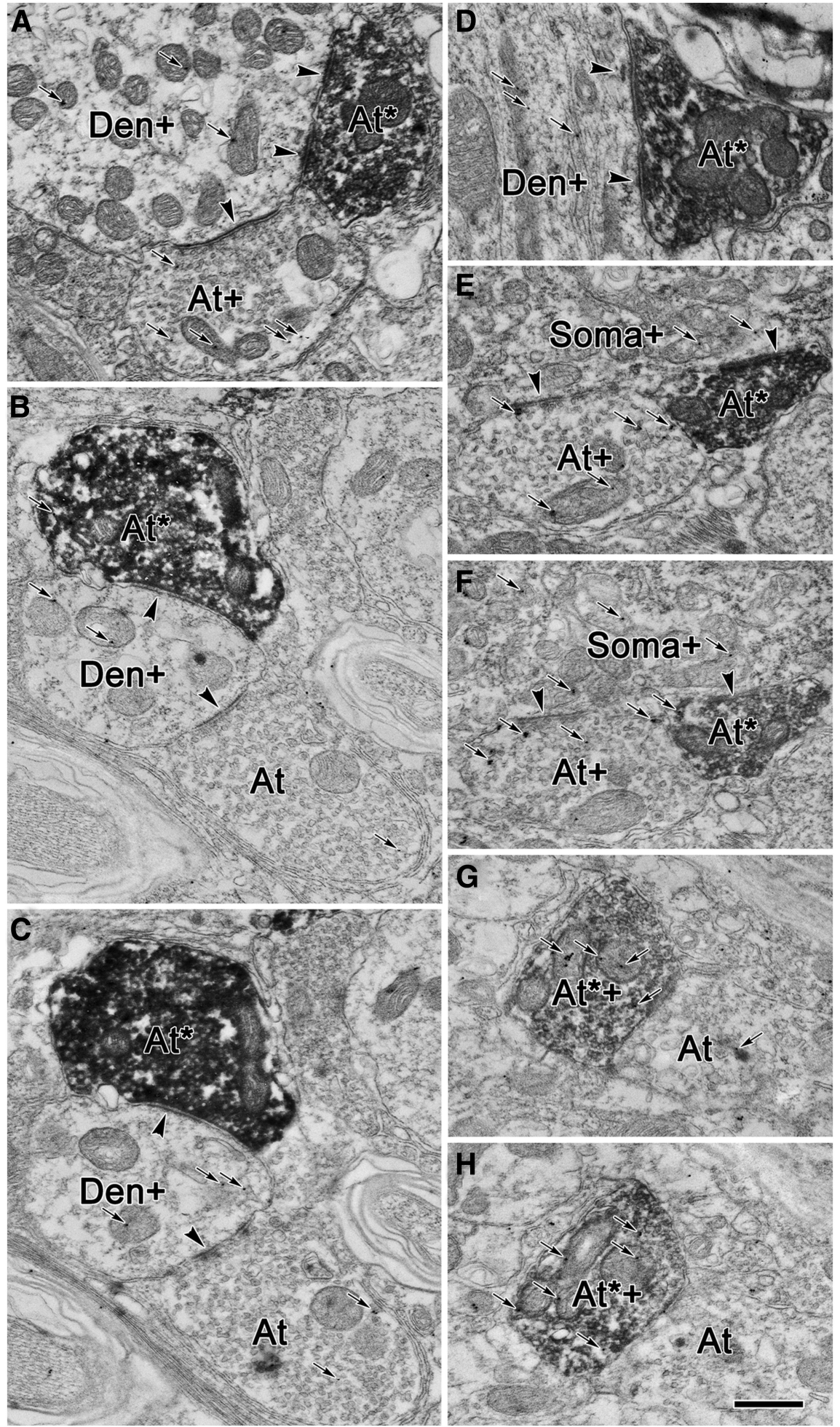

Figure 10. Glycineric profiles in RIP. $A-H$, Examples from individual sections $(A, D)$ and from semiserial pairs of sections $(B, C, E-H)$ are shown. The majority of cMRF terminals labeled with BDA (At*) were not glycine positive $\left(A t^{*} ; A-F\right)$, but a small numberwere $\left(A t^{*}+; G, H\right)$ as indicated by the presence of gold particles (small arrows). The terminals not labeled with BDA included both glycine-positive (At + ) and glycine-negative (At) populations. BDA-labeled terminals were observed to be in synaptic contact (arrowheads) with both dendrites (A-D) and somata $(\boldsymbol{E}, \boldsymbol{F})$. As judged by the number of gold particles, or their presence in semiserial sections, these postsynaptic elements included both glycine-positive somata (Soma +) and glycine-positive dendrites (Den+). Scale bar: $\boldsymbol{H}$ (for $\boldsymbol{A}-\boldsymbol{G}), 0.5 \mu \mathrm{m}$.

to saccade release (Waitzman et al., 2000b), although it should be noted that RIP lesions do not produce this result (Kaneko, 1996; Schultz et al., 2010).

There is other evidence for the cMRF's oculomotor role. Electrical stimulation of this region produces contraversive horizontal saccades (Cohen and BüttnerEnnever, 1984; Cohen et al., 1985), and three-fourths of the cells Waitzman et al. (1996) recorded in the cMRF have firing patterns that display saccade-related activity similar to those of pontine long-lead burst neurons (LLBNs). Scudder et al. (1996) recorded saccade-relate activity in primate MRF neurons, which they subsequently intra-axonally injected. These axons made very dense, bilateral arborizations within RIP. Although it is not certain which of their MRF cells fall within the cMRF, these findings agree with the LM and EM evidence in the present study for a direct cMRF projection onto RIP neurons, supporting the contention that cMRF efferents with saccade-related activity are likely to modulate OPN activity.

This raises the question of which of the physiological classes of cMRF neuron might supply the RIP with inhibitory input. Cromer and Waitzman (2006) found that the highest correlation between eye movement characteristics and activity was in a subclass of cMRF neurons coding for the duration of the saccade. The duration of OPN suppression is also highly correlated with saccade duration (Yoshida et al., 1999). This conformity between the cMRF duration cells and RIP neurons suggests that CMRF inhibitory reticuloraphe projections may carry duration signals, which help turn off OPNs at the beginning of saccades and set them free at the end of the eye movement. Thus, the trans-cMRF tectal pathway to RIP (Fig. 11) may allow the cMRF to extract duration signals appropriate to gate OPN activity from the tectal input it receives, although cMRF inputs from the frontal eye fields may also play a role (Huerta et al., 1986; Stanton et al., 1988).

The GABAergic cMRF input is not the sole player in causing the saccade-related pause in OPNs, as it has been demonstrated that strychnine, a glycinergic blocker, eliminates OPN pauses when injected into the RIP of cats, and bicuculline, a GABA antagonist, does not (Kanda et al., 2007). Furthermore, injection of muscimol, a GABA agonist, into the mon-

were GABA positive. This supports the idea that OPN firing may be regulated by GABAergic cMRF inputs (Waitzman et al., 2000b; Soetedjo et al., 2002). Another support for this hypothesis is that cMRF inactivation with muscimol can lead key RIP does not produce saccade release, only changes in saccade duration and velocity (Soetedjo et al., 2002). Clearly, the cMRF is only a part of the circuitry gating OPN activity during saccades. Several RIP inputs have been suggested to regulate OPN pauses, 


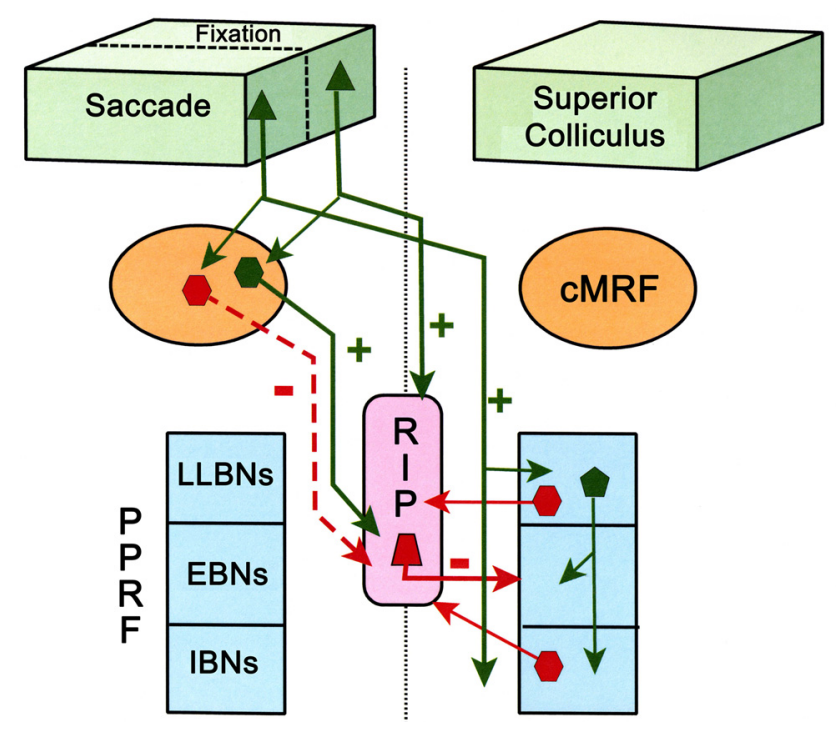

Figure 11. Schematic diagram of connections of the CMRF and the nucleus RIP in a circuit model for control of fixation and saccades. During saccades, the $\mathrm{SC}$ activates EBNs and IBNs in the PPRF, either directly or via LLBNs. cMRF neurons also receive saccade signals from SC. The GABAergic inhibitory CMRF reticuloraphe neurons help shut down glycinergic RIP activity, which in turn disinhibits EBNs and IBNs. Glycinergic inhibitory projections from the PPRF also contribute to silencing the omnipause cells. During fixation, SC fixation zone neurons send excitatory predorsal bundle inputs to RIP, which activates OPNs. These in turn suppress the activity of EBNs and IBNs. Non-GABAergic CMRF neurons also receive input from the $S C$ fixation neurons and contribute to the fixationrelated activation of RIP neurons. Solid green line arrows and " +" stand for excitatory projections, and dashed red line arrows and "-" indicate GABAergic inhibitory projections. Solid red line arrows and - indicate inhibitory glycinergic projections.

including pontine LLBNs and medullary IBNs, as cells throughout the pontomedullary reticular formation project to the RIP (Langer and Kaneko, 1984, 1990; Fig. 11). There is also physiological evidence that both regions inhibit OPNs (Hepp et al., 1989; Kamogawa et al., 1996; Izawa et al., 1999; Yoshida et al., 1999). However, the specific pontine LLBNs that are responsible have not been identified. Furthermore, intra-axonal staining of identified IBNs failed to label terminals in the OPN area of cats (Yoshida et al., 1982) or monkeys (Strassman et al., 1986), suggesting that the medullary cells projecting to RIP are probably not conventional IBNs. Certainly, the presence of the trans-cMRF pathway demonstrated here does not negate the likelihood of other sources of regulatory input to the OPNs, particularly glycinergic ones. Nevertheless, in view of the substantial glycinergic and GABAeric input to RIP neurons (Horn et al., 1994; present data), it is likely that their characteristic pauses are modulated by both types of sources.

\section{The cMRF may also send excitatory inputs to RIP}

In the present study, approximately one-third of the cMRF reticuloraphe terminals were not GABA positive. As noted in Results, a portion of these non-GABAergic terminals were probably produced by uptake by predorsal bundle axons. However, many of the non-GABAergic terminals labeled following cMRF injections had more diffusely organized vesicles than those commonly observed following SC injections. It is possible that they failed to immunostain due to the presence of the $\mathrm{DAB}$ reaction product (Bokor et al., 2005). Alternatively, they may truly represent excitatory reticuloraphe projections, as GABA-negative terminals are also present following PhaL injections. In line with this, unilateral electrical microstimulation of some sites in the cMRF can sup- press saccades, and bilateral stimulation can induce fixation (Cohen et al., 1985). Thus, the cMRF may also contain excitatory projections to RIP that help maintain fixation (Fig. 11).

There is anatomical and electrophysiological evidence that the rostral SC sends direct excitatory inputs to OPNs via predorsal bundle fibers (Paré and Guitton, 1994; Büttner-Ennever et al., 1999; Takahashi et al., 2005). In agreement with this, the ultrastructural features of tectoraphe terminals observed here suggest an excitatory nature (Fig. 11), although our analysis was not extensive enough to allow division into the terminal subcategories observed by Büttner-Ennever et al. (1999). Neurons in the rostral pole of the SC that display tonic activity during fixation have been described in cats and monkeys (Munoz and Guitton, 1989, 1991; Peck, 1989; Munoz and Wurtz, 1993a,b; Gandhi and Keller, 1999). This rostral SC area differs in several features from the rest of the colliculus; for instance, its tectotectal connections are mutually excitatory (Munoz and Istvan, 1998; Takahashi et al., 2005, 2007). Physiological studies indicate that direct activation of OPNs by rostral SC neurons can, at best, play a supportive role during fixation (Paré and Guitton, 1994; Kaneko, 1996; Gandhi and Keller, 1999), as there are differences between the discharges of rostral SC neurons and those of OPNs (King et al., 1980; Munoz and Wurtz, 1993b; Everling et al., 1998). Perhaps the cMRF's excitatory projection helps compensate for the discharge difference between rostral SC neurons and OPNs. On the other hand, recent studies have suggested that the activity in rostral SC neurons is actually related to fixation microsaccades (Hafed et al., 2009; Hafed and Krauzlis, 2010). OPN pauses are also modulated for microsaccades (Brien et al., 2009), but how cMRF neurons function with respect to microsaccades has never been studied. Thus, establishing the role of a rostral SC-cMRF-RIP pathway awaits further investigation. In summary, the considerable and heterogeneous input that the cMRF provides to RIP may allow different elements within the SC to differentially upregulate and downregulate OPN activity in parallel with collicular mechanisms for controlling the eye during saccades and fixation.

\section{References}

Appell PP, Behan M (1990) Sources of subcortical GABAergic projections to the superior colliculus in the cat. J Comp Neurol 302:143-158. CrossRef Medline

Araki M, McGeer PL, McGeer EG (1984) Presumptive gammaaminobutyric acid pathways from the midbrain to the superior colliculus studied by a combined horseradish peroxidase-gamma-aminobutyric acid transaminase pharmacohistochemical method. Neuroscience 13: 433-439. CrossRef Medline

Bokor H, Frère SGA, Eyre MD, Slézia A, Ulbert I, Lüthi A, Acsády L (2005) Selective GABAergic control of higher-order thalamic relays. Neuron 45: 929-940. CrossRef Medline

Brien DC, Corneil BD, Fecteau JH, Bell AH, Munoz DP (2009) The behavioral and neurophysiological modulation of microsaccades in monkeys. J Eye Mov Res 3:4, 1-12.

Büttner-Ennever JA, Horn AK, Henn V, Cohen B (1999) Projections from the superior colliculus motor map to omnipause neurons in monkey. J Comp Neurol 413:55-67. CrossRef Medline

Chen B, May PJ (2000) The feedback circuit connecting the superior colliculus and central mesencephalic reticular formation: a direct morphological demonstration. Exp Brain Res 131:10-21. CrossRef Medline

Chimoto S, Iwamoto Y, Shimazu H, Yoshida K (1996) Monosynaptic activation of medium-lead burst neurons from the superior colliculus in the alert cat. J Neurophysiol 75:2658-2661. Medline

Cohen B, Büttner-Ennever JA (1984) Projections from the superior colliculus to a region of the central mesencephalic reticular formation (cMRF) associated with horizontal saccadic eye movements. Exp Brain Res 57: 167-176. Medline

Cohen B, Henn V (1972) Unit activity in the pontine reticular formation associated with eye movements. Brain Res 46:403-410. CrossRef Medline 
Cohen B, Matsuo V, Fradin J, Raphan T (1985) Horizontal saccades induced by stimulation of the central mesencephalic reticular formation. Exp Brain Res 57:605-616. Medline

Cromer JA, Waitzman DM (2006) Neurones associated with saccade metrics in the monkey central mesencephalic reticular formation. J Physiol 570:507-523. CrossRef Medline

Everling S, Paré M, Dorris MC, Munoz DP (1998) Comparison of discharge characteristics of brain stem omnipause neurons and superior colliculus fixation neurons in monkey: implications for control of fixation and saccade behavior. J Neurophysiol 79:511-528. Medline

Evinger C, Kaneko CR, Fuchs AF (1982) Activity of omnipause neurons in alert cats during saccadic eye movements and visual stimuli. J Neurophysiol 47:827-844. Medline

Gandhi NJ, Keller EL (1999) Activity of the brain stem omnipause neurons during saccade perturbed by stimulation in the primate superior colliculus. J Neurophysiol 82:3254-3267. Medline

Gerfen CR, Sawchenko PE (1984) An anterograde neuroanatomical tracing method that shows the detailed morphology of neurons, their axons and terminals: immunohistochemical localization of an axonally transported plant lectin, Phaseolus vulgaris leucoagglutinin (PHA-L). Brain Res 290: 219-238. CrossRef Medline

Hafed ZM, Krauzlis RJ (2010) Microsaccadic suppression of visual bursts in the primate superior colliculus. J Neurosci 30:9542-9547. CrossRef Medline

Hafed ZM, Goffart L, Krauzlis RJ (2009) A neural mechanism for microsaccade generation in the primate superior colliculus. Science 323:940-943. CrossRef Medline

Hepp K, Henn V, Vilis T, Cohen B (1989) Brainstem regions related to saccade generation. Rev Oculomot Res 3:105-212. Medline

Horn AK, Büttner-Ennever JA, Wahle P, Reichenberger I (1994) Neurotransmitter profile of saccadic omnipause neurons in nucleus raphe interpositus. J Neurosci 14:2032-2046. Medline

Huerta MF, Krubitzer LA, Kaas JH (1986) Frontal eye field as defined by intracortical microstimulation in squirrel monkeys, owl monkeys, and macaque monkeys: I. Subcortical connections. J Comp Neurol 253:415439. CrossRef Medline

Ito J, Markham $\mathrm{CH}$, Curthoys IS (1984) Projections to eye movementrelated pause neurons region in cat using HRP. Exp Neurol 86:93-104. CrossRef Medline

Iwamoto Y, Chimoto S, Yoshida K, Shimazu H (1997) Omnidirectional pause neurons receive an eye velocity signal during saccades in the alert cat. Soc Neurosci Abstr 23:7.

Izawa Y, Sugiuchi Y, Shinoda Y (1999) Neural organization from the superior colliculus to motoneurons in the horizontal oculomotor system of the cat. J Neurophysiol 81:2597-2611. Medline

Kamogawa H, Ohki Y, Shimazu H, Suzuki I, Yamashita M (1996) Inhibitory input to pause neurons from pontine burst neuron area in the cat. Neurosci Lett 203:163-166. CrossRef Medline

Kanda T, Iwamoto Y, Yoshida K, Shimazu H (2007) Glycinergic inputs cause the pause of pontine omnipause neurons during saccades. Neurosci Lett 413:16-20. CrossRef Medline

Kaneko CR (1996) Effects of ibotenic acid lesions of the omnipause neurons on saccadic eye movements in rhesus macaques. J Neurophysiol 75:22292242. Medline

Keller EL (1974) Participation of medial pontine reticular formation in eye movement generation in monkey. J Neurophysiol 37:316-332. Medline

Keller EL, McPeek RM, Salz T (2000) Evidence against direct connections to PPRF EBNs from SC in the monkey. J Neurophysiol 84:1303-1313. Medline

King WM, Precht W, Dieringer N (1980) Afferent and efferent connections of cat omnipause neurons. Exp Brain Res 38:395-403. Medline

Langer TP, Kaneko CR (1984) Brainstem afferents to the omnipause region in the cat: a horseradish peroxidase study. J Comp Neurol 230:444-458. CrossRef Medline

Langer TP, Kaneko CR (1990) Brainstem afferents to the oculomotor omnipause neurons in monkey. J Comp Neurol 295:413-427. CrossRef Medline

Luschei ES, Fuchs AF (1972) Activity of brain stem neurons during eye movements of alert monkeys. J Neurophysiol 35:445-461. Medline

Mooney RD, Bennett-Clarke CA, King TD, Rhoades RW (1990) Tectospinal neurons in hamster contain glutamate-like immunoreactivity. Brain Res 537:375-380. CrossRef Medline
Moschovakis AK, Karabelas AB, Highstein SM (1988a) Structure-function relationships in the primate superior colliculus. I. Morphological classification of efferent neurons. J Neurophysiol 60:232-262. Medline

Moschovakis AK, Karabelas AB, Highstein SM (1988b) Structure-function relationships in the primate superior colliculus. II. Morphological identity of presaccadic neurons. J Neurophysiol 60:263-302. Medline

Munoz DP, Guitton D (1989) Fixation and orientation control by the tectoreticulo-spinal system in the cat whose head is unrestrained. Rev Neurol (Paris) 145:567-579.

Munoz DP, Guitton D (1991) Control of orienting gaze shifts by the tectoreticulospinal system in the head-free cat. II. Sustained discharges during motor preparation and fixation. J Neurophysiol 66:1624-1641. Medline

Munoz DP, Istvan PJ (1998) Lateral inhibitory interactions in the intermediate layers of the monkey superior colliculus. J Neurophysiol 79:11931209. Medline

Munoz DP, Wurtz RH (1993a) Fixation cells in monkey superior colliculus. I. Characteristics of cell discharge. J Neurophysiol 70:559-575. Medline

Munoz DP, Wurtz RH (1993b) Fixation cells in monkey superior colliculus. II. Reversible activation and deactivation. J Neurophysiol 70:576-589. Medline

Nakao S, Curthoys IS, Markham CH (1980) Direct inhibitory projection of pause neurons to nystagmus-related pontomedullary reticular burst neurons in the cat. Exp Brain Res 40:283-293. Medline

Paré M, Guitton D (1994) The fixation area of the cat superior colliculus: effects of electrical stimulation and direct connection with brainstem omnipause neurons. Exp Brain Res 101:109-122. Medline

Paxinos G, Huang X, Toga AW (2000) The rhesus monkey brain in stereotaxic coordinates. San Diego: Academic.

Peck CK (1989) Visual responses of neurons in cat superior colliculus in relation to fixation of targets. J Physiol 414:301-315. Medline

Perkins E, Warren S, May PJ (2009) The mesencephalic reticular formation as a conduit for primate gaze control: tectal inputs to neurons targeting the spinal cord and medulla. Anat Rec 292:1162-1181. CrossRef

Raybourn MS, Keller EL (1977) Colliculoreticular organization in primate oculomotor system. J Neurophysiol 40:861-878. Medline

Robinson DA (1975) Tectal oculomotor connections. Neurosci Res Program Bull 13:238-244. Medline

Schultz KP, Williams CR, Busettini C (2010) Macaque pontine omnipause neurons play no direct role in the generation of eye blinks. J Neurophysiol 103:2255-2274. CrossRef Medline

Scudder CA, Moschovakis AK, Karabelas AB, Highstein SM (1996) Anatomy and physiology of saccadic long-lead burst neurons recorded in the alert squirrel monkey. I. Descending projections from the mesencephalon. J Neurophysiol 76:332-352. Medline

Shinoda Y, Sugiuchi Y, Izawa Y, Takahashi M (2008) Neural circuits for triggering saccades in the brainstem. Prog Brain Res 171:79-85. CrossRef Medline

Soetedjo R, Kaneko CR, Fuchs AF (2002) Evidence that the superior colliculus participates in the feedback control of saccadic eye movements. J Neurophysiol 87:679-695. Medline

Sparks DL (1978) Functional properties of neurons in the monkey superior colliculus: coupling of neuronal activity and saccade onset. Brain Res 156:1-16. CrossRef Medline

Stanton GB, Goldberg ME, Bruce CJ (1988) Frontal eye field efferents in macaque monkey: I. Subcortical pathways and topography of striatal and thalamic terminal fields. J Comp Neurol 271:473-492. CrossRef Medline

Strassman A, Highstein SM, McCrea RA (1986) Anatomy and physiology of saccadic burst neurons in the alert squirrel monkey. II. Inhibitory burst neurons. J Comp Neurol 249:358-380. CrossRef Medline

Strassman A, Evinger C, McCrea RA, Baker RG, Highstein SM (1987) Anatomy and physiology of intracellularly labelled omnipause neurons in the cat and squirrel monkey. Exp Brain Res 67:436-440. Medline

Sugiuchi Y, Izawa Y, Takahashi M, Na J, Shinoda Y (2005) Physiological characterization of synaptic inputs to inhibitory burst neurons from the rostral and caudal superior colliculus. J Neurophysiol 93:697-712. CrossRef Medline

Takahashi M, Sugiuchi Y, Izawa Y, Shinoda Y (2005) Commmissural excitation and inhibition by superior colliculus in tectoreticular neurons projecting to omnipause neuron and inhibitory burst neuron regions. J Neurophysiol 94:1707-1726. CrossRef Medline

Takahashi M, Sugiuchi Y, Shinoda Y (2007) Commissural mirrorsymmetric excitation and reciprocal inhibition between the two superior 
colliculi and their roles in verical and horizontal eye movements. J Neurophysiol 98:2664-2682. CrossRef Medline

Vidal PP, May PJ, Baker R (1988) Synaptic organization of the tectal-facial pathways in the cat. I. Synaptic potentials following collicular stimulation. J Neurophysiol 80:769-797. Medline

Waitzman DM, Silakov VL, Cohen B (1996) Central mesencephalic reticular formation (cMRF) neurons discharging before and during eye movements. J Neurophysiol 75:1546-1572. Medline

Waitzman DM, Silakov VL, DePalma-Bowles S, Ayers AS (2000a) Effects of reversible inactivation of the primate mesencephalic reticular formation. I. Hypermetric goal-directed saccades. J Neurophysiol 83:2260-2284. Medline

Waitzman DM, Silakov VL, DePalma-Bowles S, Ayers AS (2000b) Effects of reversible inactivation of the primate mesencephalic reticular formation. II. Hypometric vertical saccades. J Neurophysiol 83:2285-2299. Medline

Wang N, Warren S, May PJ (2009) Ultrastructural evidence the central mesencephalic reticular formation may depress omnipause neuron activity for tectally evoked saccades. Soc Neurosci Abstr 35:851.9.

Wang N, Warren S, May PJ (2010) The macaque midbrain reticular formation sends side-specific feedback to the superior colliculus. Exp Brain Res 201:701-717. CrossRef Medline

Warren S, Waitzman DM, May PJ (2008) Anatomical evidence for interconnections between the central mesencephalic reticular formation and cervical spinal cord in the cat and macaque. Anat Rec 291:141-160. CrossRef

Wong-Riley M (1979) Changes in the visual system of monocular sutured or enucleated cats demonstrable with cytochrome oxidase histochemistry. Brain Res 171:11-28. CrossRef Medline

Wurtz RH, Goldberg ME (1972) Activity of superior colliculus neurons in behaving monkey. III. Cells discharging before eye movements. J Neurophysiol 35:587-596. Medline

Yoshida K, McCrea R, Berthoz A, Vidal PP (1982) Morphological and physiological characteristics of inhibitory burst neurons controlling horizontal rapid eye movements in the alert cat. J Neurophysiol 48:761-784. Medline

Yoshida K, Iwamoto Y, Chimoto S, Shimazu H (1999) Saccade-related inhibitory input to pontine omnipause neurons: an intracellular study in alert cats. J Neurophysiol 82:1198-1208. Medline

Yoshida K, Iwamoto Y, Chimoto S, Shimazu H (2001) Disynaptic inhibition of omnipause neurons following electrical stimulation of the superior colliculus in alert cats. J Neurophysiol 85:2639-2642. Medline

Zhou L, Warren S, May PJ (2008) The feedback circuit connecting the central mesencephalic reticular formation and the superior colliculus in the macaque monkey: tectal connections. Exp Brain Res 189:485-496. CrossRef Medline 